\title{
АККУМУЛЯЦИЯ ТЯЖЕЛЫХ МЕТАЛЛОВ В ДОННЫХ ОТЛОЖЕНИЯХ И ОРГАНАХ И ТКА- НЯХ СИГА (COREGONUS LAVARETUS) ОЗЕРА ИМАНДРА
}

\section{Даувальтер В.А., Терентьев П.М.}

Институт проблем промышленной экологии Севера КНЦ РАН, Anamumbl,vladimir@inep.ksc.ru

Озеро Имандра расположено на крайнем северо-западе Европейской территории России, в Мурманской области (рис. 1). Котловина озера находится в глубокой тектонической депрессии, которая простирается с севера на юг от Кольского залива Баренцева моря до Кандалакшского залива Белого моря [1]. Эта депрессия делит Мурманскую область на две части: западную - материковую, и восточную - полуостровную. Озеро Имандра - самый крупный водоем в Мурманской области и одно из крупнейших в Заполярье: длина озера - 109 км, средняя ширина - 3.19 км, площадь с остро-

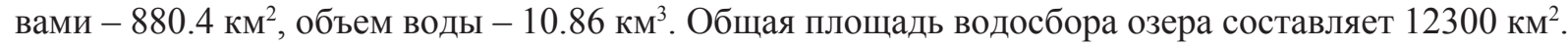

Наличие уникальных месторождений полезных ископаемых и удобное расположение на пути основных транспортных магистралей привели к развитию мощного индустриального комплекса на территории водосбора, что вызвало высокую антропогенную нагрузку на озеро [1]. Среди основных производств выделяются следующие: горнодобывающая промышленность (ОАО «Апатит»), металлургическая промышленность (ОАО «Североникель»), железорудное производство (ОАО «Олкон»), энергетический комплекс (Кольская АЭС, Апатитская ТЭЦ, каскад Нивских ГЭС), а также муниципальные стоки населенных пунктов, расположенных на водосборе озера.

С целью оценки современного экологического состояния оз. Имандра и установления закономерностей аккумуляции и биогеохимического распределения металлов в экосистеме оз. Имандра ( $\mathrm{Ni}, \mathrm{Cu}, \mathrm{Zn}, \mathrm{Mn}, \mathrm{Al}, \mathrm{Sr}, \mathrm{Hg}$ ) проведены исследования химического состава воды, донных отложений (ДО) и органов и тканей сига (Coregonus lavaretus). Отбор проб ДО производился отборником колонок гравитационного типа. Колонки ДО послойно разделялись на слои по 1 см. Отлов рыбы проводился набором жаберных сетей с различными размерами ячеи. Методика отбора и химического анализа проб ДО и органов и тканей сига подробно описана ранее [1-3]. Содержание металлов определялось методом атомной абсорбции. Для оценки интенсивности накопления металлов в органах и тканях сига рассчитывались величины коэффициента биологического накопления как отношение среднего содержания элемента в органе (в мкг/Г в пересчете на сухой вес) к средней концентрации элемента в поверхностном (0-1 см) слое ДО оз. Имандра (также в мкг/г) $\left(\mathrm{KБН}_{\text {до }}\right)$ и к средней концентрации элемента в воде в мкг/л $\left(\mathrm{KБН}_{\text {водА }}\right)$. Озеро условно было разбито на пять акваторий, в различной степени подверженных антропогенному влиянию, - северная (влияние стоков ОАО «Олкон» и комбината «Североникель»), центральная и южная (влияние стоков ОАО «Апатит») части Большой Имандры, Йокостровская Имандра (транзит загрязняющих веществ из Большой Имандры) и Бабинская Имандра (условно фоновая акватория). По этим акваториям были рассчитаны средние содержания металлов в воде, ДО, органах и тканях сига за последние десять лет. В общем итоге было проанализировано проб воды и донных отложений с 30 станций и около 150 экземпляров сигов.

Наиболее загрязненной акваторией озера является Большая Имандра, принимающая промышленные стоки медно-никелевого и апатитонефелинового производств (табл. 1). Концентрации $\mathrm{Ni}$ и $\mathrm{Cu}$ в поверхностных слоях ДО в десятки и сотни раз превышают фоновые значения. В Большой Имандре наблюдается также наибольшее содержание других тяжелых металлов - Zn (стоки комбината «Североникель»), Mn (стоки ОАО «Олкон»), а также Нg, поступающей в озеро не только со стоками медно-никелевого производства, но и в результате апатитонефелинового производства, о чем было сказано ранее [4]. Повышенные содержания Al и $\mathrm{Sr}$ в поверхностных слоях ДО в южной части Большой Имандры связаны с поступлением сточных вод ОАО «Апатит» [5]. В направлении стоковых течений в озере в плесе Йокостровская Имандра происходит уменьшение содержания исследуемых металлов, а в плесе Бабинская Имандра содержания металлов ненамного превышают или равны фоновым содержаниям, поэтому этот плес и принят условно фоновым, хотя влияние аэротехногенного загрязнения прослеживается и на этой акватории озера [6]. 
Таблица 1. Среднее содержания металлов (мкг/г сух. веса) в поверхностном (0-1 см) слое ДО, воде, органах и тканях сига различных плесов оз. Имандра.

\begin{tabular}{|c|c|c|c|c|c|c|c|c|}
\hline Плес & Объект & $\mathrm{Ni}$ & $\mathrm{Cu}$ & $\mathrm{Zn}$ & $\mathrm{Mn}$ & $\mathrm{Al}$ & $\mathrm{Sr}$ & $\mathrm{Hg}$ \\
\hline \multirow{7}{*}{$\begin{array}{l}\text { Большая Имандра } \\
\text { Север }\end{array}$} & ДО & 1523 & 287 & 104 & 28487 & 21361 & 286 & 0.089 \\
\hline & вода & 6 & 4 & 1 & 22 & 29 & 54 & н.о. \\
\hline & мышцы & 1.03 & 0.88 & 22 & 2.5 & 4.0 & 22.09 & 0.180 \\
\hline & печень & 1.6 & 35.4 & 266 & 7.3 & 10.5 & 2.8 & 0.390 \\
\hline & почки & 10.2 & 9.8 & 198 & 4.6 & 11.3 & 4.3 & 0.710 \\
\hline & жабры & 2.1 & 2.5 & 397 & 30 & 14.8 & 210 & 0.330 \\
\hline & скелет & 7.4 & 3.7 & 147 & 58.4 & 9.3 & 1199 & 0.160 \\
\hline \multirow{7}{*}{$\begin{array}{l}\text { Большая Имандра } \\
\text { Центр }\end{array}$} & До & 1860 & 370 & 131 & 10000 & 53500 & 1475 & 0.242 \\
\hline & вода & 9 & 5 & 1 & 23 & 29 & 39 & н.о. \\
\hline & мышцы & 0.52 & 1.15 & 15.5 & 1.07 & 0.77 & 4.73 & 0.140 \\
\hline & печень & 1.01 & 58.13 & 153 & 7.5 & 4.5 & 1.4 & 0.180 \\
\hline & почки & 6.8 & 6.0 & 114 & 2.9 & 8.5 & 5.6 & 0.220 \\
\hline & жабры & 1.8 & 1.8 & 337 & 13.8 & 5.5 & 124 & 0.150 \\
\hline & скелет & 2.2 & 0.4 & 105 & 40.5 & 2.6 & 577 & 0.030 \\
\hline \multirow{7}{*}{$\begin{array}{l}\text { Большая Имандра } \\
\text { Юг }\end{array}$} & ДО & 989 & 299 & 339 & 5600 & 48800 & 1980 & 0.267 \\
\hline & вода & 6 & 4 & 1 & 14 & 86 & 74 & н.о. \\
\hline & мышцы & 0.69 & 0.80 & 23 & 1.74 & 2.58 & 14.2 & 0.150 \\
\hline & печень & 1.6 & 41.9 & 204 & 9.0 & 8.0 & 12.2 & 0.150 \\
\hline & почки & 4.3 & 8.1 & 178 & 4.9 & 10.7 & 11.6 & 0.250 \\
\hline & жабры & 2.8 & 2.7 & 411 & 29 & 101 & 210 & 0.110 \\
\hline & скелет & 2.9 & 0.8 & 152 & 41 & 5.5 & 859 & 0.070 \\
\hline \multirow{7}{*}{$\begin{array}{l}\text { Йокостровская } \\
\text { Имандра }\end{array}$} & ДО & 766 & 203 & 101 & 11700 & 25000 & 609 & 0.154 \\
\hline & вода & 5.25 & 3 & 1 & 13 & 26 & 60 & н.о. \\
\hline & мышцы & 0.82 & 0.75 & 19.1 & 1.94 & 2.54 & 13.9 & 0.185 \\
\hline & печень & 1.6 & 32 & 244 & 8.8 & 9.68 & 6.5 & 0.450 \\
\hline & почки & 6.1 & 7.4 & 223 & 4.9 & 26.1 & 9.6 & 0.545 \\
\hline & жабры & 2.2 & 2.2 & 446 & 20.0 & 20.2 & 159 & 0.205 \\
\hline & скелет & 5.6 & 2.4 & 146 & 40 & 7.92 & 668 & 0.155 \\
\hline \multirow{7}{*}{$\begin{array}{l}\text { Бабинская } \\
\text { Имандра }\end{array}$} & ДО & 212 & 118 & 108 & 7600 & 23300 & 66 & 0.097 \\
\hline & вода & 2 & 3 & 1 & 2.5 & 20 & 48 & н.о. \\
\hline & мышцы & 0.79 & 0.80 & 20.8 & 1.95 & 5.08 & 14.4 & 0.215 \\
\hline & печень & 1.32 & 47 & 230 & 8.77 & 7.71 & 2.27 & 0.430 \\
\hline & почки & 4.74 & 8.13 & 278 & 4.83 & 41 & 6.62 & 0.630 \\
\hline & жабры & 2.1 & 2.1 & 388 & 16.2 & 24.8 & 126 & 0.130 \\
\hline & скелет & 5.5 & 2.1 & 148 & 24.6 & 5.4 & 529 & 0.070 \\
\hline
\end{tabular}

Тяжелые металлы способны накапливаться в живых организмах в более высоких концентрациях, чем в окружающей среде. Содержание металлов в тканях рыб отражает динамику этих элементов в среде обитания и может быть использовано для мониторинга загрязнения окружающей среды, а также быть одним из показателей, раскрывающих причины наблюдаемых аномальных состояний отдельных особей и популяции в целом в условиях загрязнения водоема [7]. Количество металлов в органах и тканях рыб является переменной величиной, находящейся в тесной взаимосвязи с геохимическими условиями среды обитания, с генеративным и пластическим обменом и дру- 
гими факторами [8]. Поглощение и аккумуляция тяжелых металлов рыбами зависит от химических и физических процессов в водоеме (в воде и на поверхности ДО). Сезонные изменения влияют на количество и доступность металлов.

По способности к аккумуляции Ni органы и ткани сига оз. Имандра располагаются в следующем порядке (табл. 1): почка > скелет > жабры > печень > мышцы. Несмотря на высокое содержание Ni в воде и ДО оз. Имандра, содержание этого тяжелого металла в органах и тканях сигов невысокое (табл. 1). Ранее [8] также было отмечено, что наибольшей аккумулирующей способностью по отношению к Ni обладает почка рыб. Значения коэффициентов биологического накопления находятся в таком же порядке, что и их содержания в органах и тканях сигов (табл. 2).

Таблица 2. Средние значения коэффициентов биологического накопления металлов в органах и тканях сига оз. Имандра по отношению к их содержанию в воде $\left(\mathrm{KБН}_{\text {водА }}\right)$ и ДО $\left(\mathrm{KБН}_{\text {до }}\right)$.

\begin{tabular}{|c|c|c|c|c|c|c|c|c|}
\hline Орган & Показатель & $\mathrm{Ni}$ & $\mathrm{Cu}$ & $\mathrm{Zn}$ & $\mathrm{Mn}$ & $\mathrm{Al}$ & $\mathrm{Sr}$ & $\mathrm{Hg}$ \\
\hline \multirow{2}{*}{ мышцы } & $\mathrm{KБН}_{\text {до }}$ & 0.0013 & 0.0039 & 0.16 & 0.00019 & 0.00012 & 0.066 & 1.3 \\
\hline & $\mathrm{KБН}_{\text {ВодА }}$ & 180 & 230 & 20000 & 240 & 110 & 250 & - \\
\hline \multirow{2}{*}{ печень } & $\mathrm{KБН}_{\text {до }}$ & 0.0023 & 0.19 & 1.8 & 0.00090 & 0.00029 & 0.012 & 2.6 \\
\hline & КБН & 320 & 11500 & 220000 & 1100 & 270 & 82 & $\begin{array}{lll}- & \\
\end{array}$ \\
\hline \multirow{2}{*}{ почка } & $\mathrm{KБН}_{\text {до }}$ & 0.0090 & 0.037 & 1.6 & 0.00048 & 0.00074 & 0.028 & 4.0 \\
\hline & КБН & 1300 & 2200 & 199000 & 600 & 770 & 140 & - \\
\hline \multirow{2}{*}{ жабры } & $\mathrm{KБН}_{\text {до }}$ & 0.0036 & 0.010 & 3.1 & 0.0023 & 0.00095 & 0.62 & 1.5 \\
\hline & КБН & 490 & 630 & 396000 & 2400 & 780 & 3000 & - \\
\hline \multirow{2}{*}{ скелет } & $\mathrm{KБН}_{\text {до }}$ & 0.0085 & 0.0092 & 1.1 & 0.0040 & 0.00023 & 2.8 & 0.78 \\
\hline & КБН & 1200 & 540 & 140000 & 4050 & 210 & 14200 & - \\
\hline
\end{tabular}

Медь содержится в наибольших количествах в печени (табл. 1), что было отмечено в [8]. По содержанию Сu органы сига оз. Имандра располагаются в следующем порядке (табл. 1): печень $>$ почка > жабры > скелет > мышцы. Содержание $\mathrm{Cu}$ в печени сигов более, чем на порядок больше, чем Ni. Значения КБН тканях сигов (табл. 2), причем эти значения намного больше, чем для Ni (за исключением скелета).

Уровень накопления Zn в органах и тканях сигов оз. Имандра довольно высокий, несмотря на относительно низкое содержание этого тяжелого металла в воде и ДО озера. По концентрации $\mathrm{Zn}$ органы сига оз. Имандра располагаются в следующем порядке (табл. 1): жабры > печень > почка > скелет > мышцы. Подобный порядок аккумуляции Zn в органах и тканях сига оз. Имандра был отмечен ранее [1], но содержание этого металла в органах сига в последние годы снижается. Значения

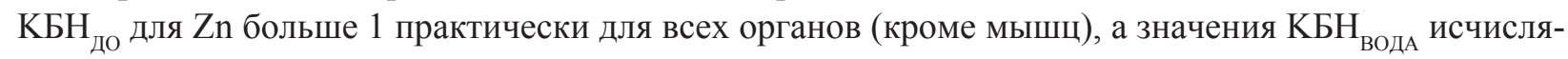
ются сотнями тысяч, что говорит о значительном накоплении в органах и тканях сигов этого эссенциального элемента.

По аккумуляции Mn органы сига оз. Имандра располагаются в следующем порядке (табл. 1): скелет > жабры > печень > почка > мышцы. Наибольшее количество Mn в скелете, жабрах и мышцах сигов накопилось на севере Большой Имандры, куда длительное время поступали стоки железорудного производства с ОАО «Олкон», где отмечаются максимальные содержания сопутствующего этому производству Мn в воде и ДО. Значения коэффициента корреляции содержания Mn в скелете и воде и ДО достигает достоверной величины и равно 0.82. Эта закономерность в оз. Имандра отмечена ранее [1]. Коэффициенты биологического накопления Мn в организме сигов невысокие и минимальны среди всех исследуемых металлов и располагаются в том же порядке среди органов, что и их аккумуляция (табл. 2).

По содержанию $\mathrm{Al}$ органы сига оз. Имандра располагаются в следующем порядке (табл. 1): жабры > почка > печень > скелет > мышцы. Отмечена высокая степень зависимости содержания Al 
в жабрах от концентрации в воде $(\mathrm{r}=0.95)$, что было отмечено ранее [8], и связывается с процессами его осаждения на жабрах при фильтрации воды. Наибольшее содержание Al в жабрах сига обнаружено в южной части Большой Имандры, куда поступают стоки апатитонефелинового производства, содержащие высокие концентрации Al (табл. 1). Коэффициенты биологического накопления $\mathrm{Al}$ в организме сигов невысокие и минимальны среди всех исследуемых металлов (наряду с $\mathrm{Mn}$ ) и располагаются в том же порядке среди органов, что и их аккумуляция (табл. 2).

Участие $\mathrm{Sr}$ в обменных процессах в костной ткани приводит к интенсивной аккумуляции этого металла в скелете рыб, в том числе и сига $[1,8]$. По способности к аккумуляции Sr органы и ткани сига оз. Имандра располагаются в следующем порядке (табл. 1): скелет > жабры > мышцы > почка > печень. Со стоками апатитонефелинового производства в южную часть Большой Имандры $\mathrm{Sr}$ в больших количествах поступает в воду и ДО. Обладая большой биофильностью $\mathrm{Sr}$ характеризуется высокой величиной КБН до в скелете сигов - 2.8 (табл. 2.)

Ввиду крайне низких содержаний в воде, загрязнение $\mathrm{Hg}$ можно выявить преимущественно на основе изучения ее содержания в ДО и рыбах. По концентрации Нg органы сига оз. Имандра располагаются в следующем порядке (табл. 1): почка > печень $>$ жабры > мышцы > скелет. По-

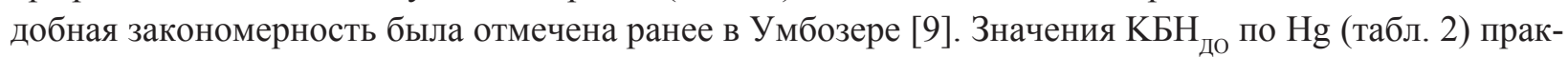
тически для всех органов выше единицы (кроме скелета), что говорит о высокой аккумуляционной способности этого токсичного металла.

\section{Литература}

1. Моисеенко Т.И., Даувальтер В.А., Лукин А.А. и др. (Под ред. Моисеенко Т.И.) Антропогенные модификации экосистемы озера Имандра. М.: Наука. 2002. 487 с.

2. Даувальтер В.А. Закономерности осадконакопления в водных объектах Европейской субарктики (природоохранные аспекты проблемы) // Автореф. дис. д.г.н. Апатиты: КНЦ РАН. 1999. 52 с.

3. Даувальтер В.А. Геоэкология донных отложений озер. Мурманск: Изд-во Мурманского гос. техн. унта. 2012. $242 \mathrm{c}$.

4. Даувальтер В.А., Кашулин Н.А. Ртуть в донных отложениях озера Имандра в зоне влияния стоков разработки апатитонефелиновых месторождений // Тр. Ферсмановской научной сессии ГИ КНЦ РАН. 2014. № 11. C. 70-75.

5. Даувальтер В.А., Кашулин Н.А. Реконструкция накопления элементов в озере Имандра как отражение динамики качества воды // Тр. Ферсмановской научной сессии ГИ КНЦ РАН. 2016. № 13. С. 218-221.

6. Даувальтер В.А., Кашулин Н.А. Современное экологическое состояние озера Имандра // Север и Арктика в новой парадигме мирового развития. Лузинские чтения - 2016. Апатиты: ИЭП КНЦ РАН. 2016. С. 197-204.

7. Кашулин Н.А., Даувальтер В.А., Кашулина Т.Г и др. Антропогенные изменения лотических экосистем Мурманской области. Ч. 1. Апатиты: Изд-во КНЦ РАН. 2005. 234 с.

8. Моисеенко Т.И. Влияние геохимических факторов водной среды на биоаккумуляцию металлов в организме рыб // Геохимия. 2015. № 3. С. 222-233.

9. Даувальтер В.А., Кашулин Н.А. Халькофильные элементы (Hg, Cd, Pb, As) в озере Умбозеро, Мурманская область // Водные ресурсы. 2010. Т. 37. № 4. С. 461-476. 